\title{
Tingkat Kepuasan Petani Terhadap Aspek Organisasi Gapoktan Di Kecamatan Gandusari, Kecamatan Talun, dan Kecamatan Kademangan
}

\author{
Edya Moelia Moeis ${ }^{1}$, Supardi ${ }^{1}$ \\ ${ }^{1}$ Faskultas Peternakan Universitas Islam Balitar \\ Email: edyamoelia@gmail.com
}

\begin{abstract}
ABSTRAK
Penelitian ini bertujuan untuk mengetahui kepuasan petani terhadap aspek organisasi Gapoktan (Gabungan Kelompok Petani) Di Kabupaten Blitar. Penelitian ini menggunakan metode RAL (Rancangan Acak Lengkap). Jumlah responden sebanyak 27 orang yang diambilsecara proporsional random sampling dari 10 kelompok tani yang terdaftar Di Kabupaten Blitar. Responden diberikan 7 point pertanyaan yang berkaitan dengan aspek organisasi Gapoktan yang masing-masing memiliki kumulatif skor penilaian yang diwakilkan dari skor angka 1sampai 5, dimana setiap angka mewakili keterangan sangat tidak memuaskan, tidakmemuaskan, cukup menerima, memuaskan, dan sangat memuaskan. Didapatkan hasil bahwa petani cukup menerima dengan aspek organisasi dari gapoktan masing-masing, Banyak faktor yang mempengaruhi hasil akhir dari kuisioner yang diberikan pada responden, faktor utama adalah pemahaman responden untuk memahami soal, faktor pemahaman ini sangat dipengaruhi oleh tingkat pendidikan dan umur.
\end{abstract}

Kata Kunci : Gapoktan, Kepuasan, Aspek Organisasi, Kabupaten Blitar

ABSTRACT
This study aims to determine the satisfaction of farmers with the organizational aspects of Gapoktan (Farmers Groups Association) in Regency of Blitar. This study uses the RAL method (Completely Randomized Design). The number of respondents was 27 people, which were taken by proportional random sampling from 10 farmer groups registered in the Regency of Blitar. Respondents were given 7 point questions related to organizational aspects of Gapoktan. Each question has a cumulative assessment score that was represented by scoring level from 1 to 5 (very dissatisfied, dissatisfied, somewhat satisfied, satisfied, and very satisfied). The obtained result shows that farmers quite satisfied the organizational aspects of each respective farmer groups. Many factors affect the final results of the questionnaire given to respondents. The main factor is the understanding of respondents about the given problem and this understanding factor is strongly influenced by their level of education and age.

Keywords: Gapoktan, Satisfaction, Organizational Aspects, Regency of Blitar

\section{Pendahuluan}

Gabungan kelompok tani asdalah kumpulan dari beberapa kelompok tani yang bergabung dan bekerja sama untuk meningkatkan skala ekonomi dan efisiensi usaha sesuai yang diungkapkan (Farida, 2012), dinamika kelompok yang diartikan sebagai gerak atau kekuatan yang terdapat di dalam kelompok, yang memerlukan atau yang berpengaruh terhadap perilaku kelompok dan anggotanya dalam mencapai tujuan, kelompok tani pada dasarnya, adalah kelompok organisasi nonformal yang ada di pedesaan yang di tumbuh kembangkan dari, oleh, dan untuk petani dengan ciri-ciri sebagai berikut. Saling mengenal, akrab dan saling percaya antar sesama anggota, mempunyai pandangan dan kepentingan yang sama dii bidang pertanian, serta ada 


\section{Jurnal Sains Peternakan}

Volume 8 No. 1, Juni 2020, pp:12-21

ISSN $2579-4450$

pembagian tugas dan tanggung jawab sesama anggota berdasarkan kesepakatan bersama.

Latar belakangang dilakukanya penelitian ini melihat mayoritas masyarakat di Kabupaten Blitar yang mengandalkan ekonomi di sektor pertanian, sehingga tentu gapoktan disini berperan sebagai wadah dari petani-petani untuk keberlanjutan usaha tani itu sendiri. Gapoktan merupakan suatu organisasi yang memiliki beberapa aspek pendukung, yaitu keberadaan AD/ART (anggaran dasar atau anggaran rumah tangga) gapoktan, rencana kerja gapoktan, rapat pengurus gapoktan, berita acara pendirian gapoktan, kelengkapan administrasi gapoktan, kepemilikan badan hukum gapoktan, dan ketepatan waktu pelaksanaan rapat akhir tahun gapoktan sesuai dengan pendapat Fuad dan Lukman (2010) aspek-aspek organisasi penting adanya guna sebagai dasar bagi gapoktan menjalankan tugasnya sebagai penyedia jasa bagi petani. Tujuan dengan adanya penelitian ini untuk melihat kepuasan petani terhadap aspek organisasi dari gapoktan di tiga kecamatan di Kabupaten Blitar.

\section{Metedeologi Penelitian}

Penelitian ini dilaksanakan di tiga kecamatan Di Kabupaten Blitar, yaitu Kecamatan Talun, Kecamatan Gandusari, dan Kecamatan Kademangan. Tiga kecamatan tersebut dipilih dengan mempertimbangkan jumlah petani dari tiga kecamatan tersebut merupakan yang tertinggi di Kabupaten Blitar. Penentuan responden sebanyak 27 yang diambil secara proportional random sampling dari 10 kelompok tani yang terdaftar di tiga kecamatan tersebut. Pengambilan data pada penelitian kali ini menggunakan dua teknik pengambilan data yaitu data primer dan data sekunder, data primer diperoleh dengan cara responden mengisi kuisioner, sedangkan data sekunder diperoleh dari data-data yang terdapat pada instansi terkait. Variabel yang diukur pada penelitian kali ini adalah tingkat kepuasan petani terhadap aspek organisasi gapoktan, penelitian ini terdiri dari 7 variabel yang telah melalui uji validitas dan reabilitas. Analisa hasil menggunakan RAL dan IPA (Index Performance Analisys) dengan diagram kartesius.

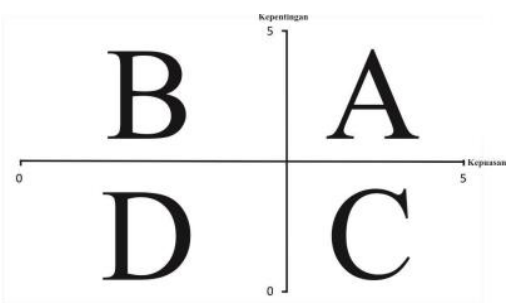

Gambar 1. Model pemetaan kuadran diagram kartesius 
Pada diagram kartesius ini penulis mengganti sumbu $X$ menjadi sumbu Kepuasan, sedangkan sumbu $Y$ menjadi sumbu Kepentingan, sedangkan pemberian notasi huruf Alfa, Bravo, Charlie, dan Delta (A, B, C, dan D) pada setiap segmen dengan tujuan agar pembaca lebih mudah membaca dan menelaah data dari diagram. Notasi A, memiliki pengertian bahwa sebaran data yang ada pada segmen tersebut menunjukan nilai kepentingan dan kepuasan yang tinggi dari segi penilaian responden. Notasi B, memiliki pengertian bahwa sebaran data yang ada pada segmen tersebut menunjukan nilai Kepentingan yang tinggi namun kepuasan yang rendah. Notasi C, memiliki pengertian bahwa sebaran data yang ada pada segmen tersebut menunjukan nilai Kepentingan yang rendah namun kepuasan tinggi. Sedangkan Notasi D, memiliki pengertian bahwa sebaran data yang ada pada segmen tersebut menunjukan nilai kepentingan dan kepuasan yang rendah.

\section{Hasil Dan Pembahasan}

Karakteristik Responden Karakteristik responden diukur berdasarkan 4 point yaitu jenis kelamin, umur, tingkat pendidikan, dan pekerjaan utama. Berikut merupakan tabel dari masing-masing point yang sudah diolah sebelumnya.

Perbandingan Jenis Kelamin Responden Berikut merupakan data tentang perbandingan jenis kelamin responden di tigakecamatan.

Tabel 1. Tabel persentase perbandingan jenis kelamin responden di tiga kecamatan

\begin{tabular}{lr}
\hline Jenis kelamin & $\mathbf{( \% )}$ \\
\hline Laki-laki & 92.59259 \\
Perempuan & 7.407407 \\
\hline Total & 100 \\
\hline \multicolumn{1}{c}{ Dari data diatas didapat dari 27 responden terdapat 25 orang berjenis kelamin }
\end{tabular}

Dari data diatas didapat dari 27 responden terdapat 25 orang berjenis kelamin laki-laki dan 2 orang berjenis kelamin perempuan.

\section{Perbandingan Umur Responden Berikut merupakan data tentang perbandingan umur responden di tiga kecamatan}

Data pada tabel 2 didapat dari 27 responden terdapat 2 orang memiliki rentang umur 30- 35 tahun, 2orang memiliki rentan gumur35-40 tahun, 4orang memiliki rentang umur 40- 45tahun, 3orang memiliki rentang umur 45-50tahun,7orang memliki rentang umur 50- 55 tahun, 1 orang memiliki rentang umur 55-60 tahun, 5 orang memiliki rentang umur 60-65 tahun, dan 3 orang memilik umur lebih dari 65 tahun. 


\section{Jurnal Sains Peternakan}

Volume 8 No. 1, Juni 2020, pp:12-21

ISSN 2579-4450

Tabel 2. Tabel persentase perbandingan umur responden di tiga kecamatan

\begin{tabular}{lr}
\hline Umur & $\mathbf{( \% )}$ \\
\hline $\mathbf{3 0 - 3 5}$ & 7.41 \\
$\mathbf{3 5}-\mathbf{4 0}$ & 7.41 \\
$\mathbf{4 0 - 4 5}$ & 14.8 \\
$\mathbf{4 5 - 5 0}$ & 11.1 \\
$\mathbf{5 0 - 5 5}$ & 25.9 \\
$\mathbf{5 5 - 6 0}$ & 3.7 \\
$\mathbf{6 0 - 6 5}$ & 18.5 \\
$\mathbf{6 5}>$ & 11.1 \\
\hline Total & 100 \\
\hline
\end{tabular}

Tingkat Pendidikan Berikut merupakan data tentang tingkatpendidikan responden di tiga kecamatan.

Tabel 3. Tabel persentase tingkat pendidikan responden di tiga kecamatan

\begin{tabular}{lr}
\hline Pendidikan & $\mathbf{( \% )}$ \\
\hline S1 & 7.4074 \\
D3 & 11.111 \\
SMA & 48.148 \\
SMP & 14.815 \\
SD & 14.815 \\
TIDAK TAMAT SD & 3.7037 \\
\hline TOTAL & 100 \\
\hline
\end{tabular}

Dari data diatas dari 27 responden terdapat 2 orang lulus derajat pendidikan S1, 3 orang lulus derajat pendidikan D3, 13 orang lulus derajat pendidikan SMA, 4 orang lulus derajat pendidikan SMP, 4 orang lulus derajat pendidikan SD, dan 1 orang tidak lulus derajat pendidikan SD.

\section{PekerjaanUtama}

Berikut merupakan data tentang tingkat pendidikan responden di tiga kecamatan.

Tabel 4. Tabel persentase tingkat pendidikan responden di tiga kecamatan

\begin{tabular}{ll}
\hline Pekerjaan & $\mathbf{( \% )}$ \\
\hline Petani & 59.26 \\
Petani/Peternak & 22.22 \\
Petani/Perikanan & 3.704 \\
Petani/Pedagang & 3.704 \\
Petani/Perangkat desa & 11.11 \\
\hline Total & 100 \\
\hline \multicolumn{1}{c}{ Dari data diatas dari 27 responden terdapat 16 orang fokus bekerja sebagai }
\end{tabular}

petani, 6 orang sebagai petani dan peternak, 1 orang sebagai peyani dan budidayawan 


\section{Jurnal Sains Peternakan}

Volume 8 No. 1, Juni 2020, pp:12-21

ISSN 2579-4450

ikan, 1 orang sebagai petani dan pedagang, dan 3 orang sebagai aparatur desa dan petani.

\section{Analisis Tingkat Kepuasan Petani Terhadap Aspek Organisasi Gapoktan}

Kepuasan Petani Terhadap AD/ART GAPOKTAN Dari 27 responden (100\%), 1 orang (3.7\%) menganggap sangat tidak memuaskan, 8 orang (29.6\%) menganggap tidak memuaskan, 12 orang (44.4\%) menganggap cukup, dan 6 orang (22.2\%) menganggap puas. Berikut merupakan tabel anova dari pengolahan dataAD/ART

Tabel 5. Tabel anova pengolahan data $\mathrm{AD} / \mathrm{ART}$

\begin{tabular}{|l|l|l|l|l|l|l|}
\hline keterangan & $\mathrm{db}$ & $\mathrm{jk}$ & $\mathrm{Kt}$ & Fhit & $\mathrm{f}$ tabel & \\
\cline { 1 - 1 } & & & & & 0.05 & 0.01 \\
\hline perlakuan & 2 & 7.78 & 3.89 & $9.69^{* *}$ & & \multirow{2}{*}{3.4} \\
\hline galat & 24 & 9.62 & 0.40 & & \\
\hline total & 26 & 17.40 & & & & \\
\hline
\end{tabular}

Tabel 6. Uji LSD aspek organisasi kepuasan AD/ART Gapoktan

\begin{tabular}{|l|l|l|l|}
\hline No. & Perlakuan & Rata-rata & Notasi \\
\hline 1 & P1 & 2.285714 & $\mathrm{a}$ \\
\hline 2 & P2 & 2.692308 & $\mathrm{a}$ \\
\hline 3 & P3 & 3.714286 & $\mathrm{~b}$ \\
\hline
\end{tabular}

AD/ART merupakan bagian tahapan pendirian Gapoktan. Putra (2016) mengemukakan $\mathrm{AD} / \mathrm{ART}$ berisi tentang kumpulan aturan tertulis yang dibuat dari, oleh dan untuk anggota sebagai pedoman kerja bagi Gapoktan yang bersifat mengikat dan berlaku pada suatu tempat dan waktu tertentu. Dari data diatas diketahui bahwa f hitung lebih besar dari pada $\mathrm{f}$ tabel, maka terdapat perbedaan yang nyata terkait dengan kepuasan petani terhadap AD/ART Gapoktan (H1 diterima), sedangkan nilai rata-rata dari perlakuan 1 (Kecamatan Talun) dan perlakuan 2 (Kecamatan Gandusari) sama, namun keduanya berbeda dengan rata- rata perlakuan 3 (Kecamatan Kademangan), ini menunjukan adanya perbedaan, baik pemahaman anggota terhadap AD/ART atau kondisi tempat dan lokasi yang berbeda sehingga membedakan AD/ART satu dengan yang lainya.

\section{Kepuasan Petani Terhadap Rencana KerjaGapoktan}

Dari 27 responden $(100 \%), 1$ orang (3.7\%) menganggap sangat tidak memuaskan, 11 orang (40.7\%) menganggap tidak memuaskan, 8 orang $(29.6 \%)$ menganggap cukup, 6 orang (22.2\%) menganggap puas, dan 1 orang $(3.7 \%)$ 


\section{Jurnal Sains Peternakan}

Volume 8 No. 1, Juni 2020, pp:12-21

ISSN 2579-4450

menganggap sangat puas. Berikut merupakan tabel anova dari pengolahan data Rencana Kerja Gapoktan

Tabel 7. Tabel anova pengolahan data rencana

\begin{tabular}{|l|l|l|l|l|l|l|}
\hline keterangan & $\mathrm{db}$ & $\mathrm{jk}$ & $\mathrm{Kt}$ & Fhit & $\mathrm{f}$ tabel & \\
\cline { 1 - 1 } \cline { 5 - 6 } & & & & & 0.05 & 0.01 \\
\hline perlakuan & 2 & 2.64 & 1.32 & 1.48 & 3.4 & 5.61 \\
\hline galat & 24 & 21.42 & 0.89 & & & \\
\hline total & 26 & 24.07 & & & & \\
\hline
\end{tabular}

Dari data diatas diketahui bahwa $f$ hitung lebih kecil dari pada $f$ tabel, maka tidak terdapat perbedaan yang nyata terkait dengan kepuasan petani terhadap Rencana Kerja Gapoktan (H0 diterima).

\section{Kepuasan Petani Terhadap Pelaksanaan Rapat Pengurus Gapoktan}

Dari 27 responden (100\%), 9 orang (33,3\%) menganggap tidak memuaskan, 15 orang $(55,6 \%)$ menganggap cukup, 2 orang $(7,4 \%)$ menganggap puas, dan 1 orang $(3,7 \%)$ menganggap sangat puas. Berikut merupakan tabel anova dari pengolahan data Pelaksanaa Rapat Pengurus.

Tabel 8. Tabel anova pengolahan data pelaksanaan rapat pengurus

\begin{tabular}{|l|l|l|l|l|l|l|}
\hline keterangan & $\mathrm{Db}$ & $\mathrm{jk}$ & $\mathrm{Kt}$ & fhit & $\mathrm{f}$ tabel & \\
\cline { 1 - 3 } \cline { 5 - 6 } & & & & & 0.05 & 0.01 \\
\hline perlakuan & 2 & 0.44 & 0.22 & 0.39 & 3.4 & 5.61 \\
\hline Galat & 24 & 13.62 & 0.56 & & & \\
\hline Total & 26 & 14.07 & & & & \\
\hline
\end{tabular}

Dari data diatas diketahui bahwa $f$ hitung lebih kecil dari pada $f$ tabel, maka tidak terdapat perbedaan yang nyata terkait dengan kepuasan petani terhadap pelaksanaan rapat pengurus Gapoktan (H0 diterima).

\section{Kepuasan Petani Terhadap Berita Acara Pendirian Gapoktan}

Dari 27 responden (100\%), 1 orang (3.7\%) menganggap sangat tidak memuaskan, 8 orang (29.6\%) menganggap tidak memuaskan, 15 orang (51.8\%) menganggap cukup,3 orang (11.1\%) menganggap puas, dan 1 orang (3.7\%) menganggap sangat puas. Berikut merupakan tabel anova dari pengolahan data Berita Acara Pendirian Gapoktan.

Tabel 9. Tabel anova pengolahan data berita acara pendirian Gapoktan

\begin{tabular}{|l|l|l|l|l|l|l|}
\hline keterangan & $\mathrm{db}$ & $\mathrm{jk}$ & $\mathrm{kt}$ & fhit & $\mathrm{f}$ tabel & \\
\cline { 1 - 3 } & & & & & 0.05 & 0.01 \\
\hline perlakuan & 2 & 1.01 & 0.50 & 0.71 & 3.4 & 5.61 \\
\hline Galat & 24 & 17.05 & 0.71 & & & \\
\hline Total & 26 & 18.07 & & & & \\
\hline
\end{tabular}




\section{Jurnal Sains Peternakan}

Volume 8 No. 1, Juni 2020, pp:12-21

ISSN 2579-4450

Dari data diatas diketahui bahwa $f$ hitung lebih kecil dari pada $f$ tabel, maka tidak terdapat perbedaan yang nyata terkait dengan kepuasan petani terhadap Berita Acara Pendirian Gapoktan (H0 diterima).

\section{Kepuasan Petani Terhadap Kelengkapan AdministrasiGapoktan}

Dari 27 responden (100\%), 2 orang (7.4\%) menganggap sangat tidakmemuaskan, 5 orang (18.5\%) menganggap tidak memuaskan, 8 orang (29.6\%) menganggap cukup,11 orang (40.7\%) menganggap puas, dan 1 orang (3.7\%) menganggap sangat puas. Berikut merupakan tabel anova dari pengolahan data Kelengkapan Administrasi Gapoktan.

Tabel 10. Tabel anova pengolahan data kelengkapan administrasi

\begin{tabular}{|l|l|l|l|l|l|l|}
\hline Keterangan & $\mathrm{db}$ & $\mathrm{jk}$ & $\mathrm{kt}$ & fhit & $\mathrm{f}$ tabel & \\
\cline { 1 - 4 } & & & & & 0.05 & 0.01 \\
\hline perlakuan & 2 & 2.57 & 1.28 & 1.24 & 3.4 & 5.61 \\
\hline Galat & 24 & 24.83 & 1.03 & & & \\
\hline Total & 26 & 27.40 & & & & \\
\hline
\end{tabular}

Dari data diatas diketahui bahwa $f$ hitung lebih kecil dari pada $f$ tabel, maka tidak terdapat perbedaan yang nyata terkait dengan kepuasan petani terhadap Kelengkapan Administrasi Gapoktan (H0 diterima).

\section{Kepuasan Petani Terhadap Badan HukumGapoktan}

Dari 27 responden (100\%), 1 orang (3.7\%) menganggap sangat tidak memuaskan, 5 orang $(18.5 \%)$ menganggap tidak memuaskan, 11 orang (40.7\%) menganggap cukup, 9 orang $(33.3 \%)$ menganggap puas, dan 1 orang $(3.7 \%)$ menganggap sangat puas. Berikut merupakan tabel anova dari pengolahan data Badan Hukum Gapoktan.

Tabel 11. Tabel anova pengolahan data badan hukum

\begin{tabular}{|l|l|l|l|l|l|l|}
\hline keterangan & $\mathrm{db}$ & $\mathrm{jk}$ & $\mathrm{kt}$ & fhit & \multicolumn{2}{|c|}{$\mathrm{f}$ tabel } \\
\cline { 1 - 4 } & & & & & 0.05 & 0.01 \\
\hline perlakuan & 2 & 1.91 & 0.95 & 1.17 & 3.4 & 5.61 \\
\hline galat & 24 & 19.49 & 0.81 & & & \\
\hline total & 26 & 21.40 & & & & \\
\hline
\end{tabular}

Dari data diatas diketahui bahwa f hitung lebih kecil dari pada $f$ tabel, maka tidak terdapat perbedaan yang nyata terkait dengan kepuasan petani terhadap Badan Hukum Gapoktan (H0 diterima).

\section{Kepuasan Petani Terhadap Penyelenggaraan Rapat Akhir Tahun Gapoktan}

Dari 27 responden (100\%), 9 orang (33.3\%) menganggap tidak memuaskan, 16 


\section{Jurnal Sains Peternakan}

Volume 8 No. 1, Juni 2020, pp:12-21

ISSN 2579-4450

orang (59.2\%) menganggap cukup, dan 2 orang (7.4\%) menganggap puas. Berikut merupakan tabel anova dari pengolahan data Penyelenggaraan Rapat Akhir Tahun Gapoktan.

Tabel 12. Tabel anova pengolahan data rapat akhir tahun Gapoktan

\begin{tabular}{|l|l|l|l|l|l|l|}
\hline keterangan & $\mathrm{db}$ & $\mathrm{jk}$ & $\mathrm{kt}$ & fhit & \multicolumn{2}{|c|}{$\mathrm{ftabel}$} \\
\cline { 1 - 1 } & & & & & 0.05 & 0.01 \\
\hline perlakuan & 2 & 0.67 & 0.33 & 0.95 & 3.4 & 5.61 \\
\hline galat & 24 & 8.50 & 0.35 & & & \\
\hline total & 26 & 9.18 & & & & \\
\hline
\end{tabular}

Dari data diatas diketahui bahwa $f$ hitung lebih kecil dari pada $f$ tabel, maka tidak terdapat perbedaan yang nyata terkait dengan kepuasan petani terhadap Penyelenggaraan Rapat Akhir Tahun Gapoktan (H0 diterima).

\section{SCORING}

Untuk menentukan nilai kinerja secara keseluruhan digunakan rumus sebagai berikut :

Skor maksimum:

$\sum$ Item Pertanyaan $\mathrm{x} \sum$ skor tertinggi yang bisa diberikan $\mathrm{x} \sum$ Respoden

$$
=7 \times 5 \times 27=945
$$

Skor minimum:

$\sum$ Item Pertanyaan $\mathrm{x} \sum$ skor terendah yang bisa diberikan $\mathrm{x} \sum$ Responden

$$
=7 \times 1 \times 27=189
$$

Interval skor $=(945-189) \div 5=151.2$

Sehingga interval skor tingkat kepuasan petani terhadap aspek organisasi gapoktan adalah sebagai berikut

189-340.2 = Sangat TidakMemuaskan

$340.2-491.4=$ Tidak Memuaskan

491.4 $-642.6=$ Cukup Menerima

642.6 $-793.8=$ Memuaskan

793.8 - 945 = SangatMemuaskan

Setelah diolah didapatkan jumlah skor kumulatif sebesar 549 point, dari point tersebut menunjukan petani merasa cukup menerima dengan aspek organisasi Gapoktan Di Kecamatan masing-masing. 
Hasil Dari Perhitungan IPA (Index Performance Analisys) Dengan menggunakan Diagram Cartesius

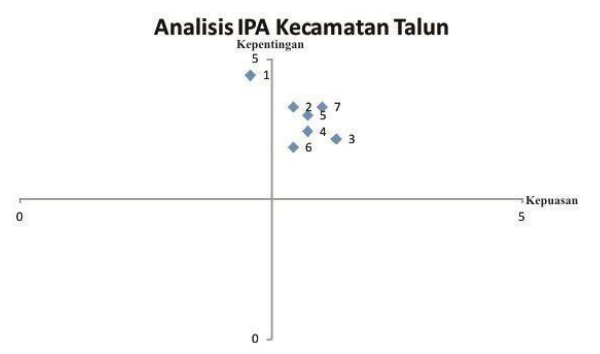

Gambar 2. Analisa IPA kecamatan talun

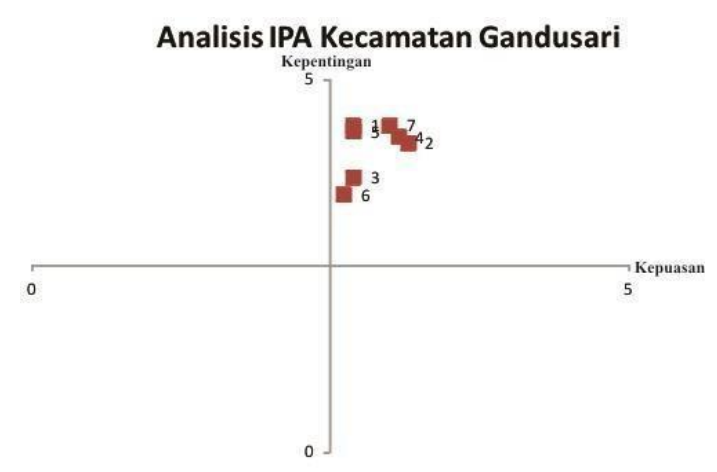

Gambar 3. Analisa IPA kecamatan Gandusari

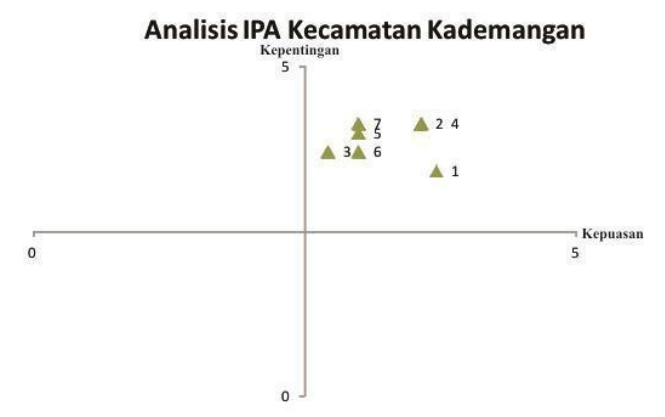

Gambar 4. Analisa IPA kecamatan Kademangan

Dari ketiga pemetaan diatas dapat diketahui bahwa dari 7 point variabel yang diberikan dari tiap tiap kecamatan hanya point 1 tentang kepuasan $\mathrm{AD} / \mathrm{ART}$ dari kecamatan talun berada di kuadran B yang berarti bagi anggota pada gapoktan kecamatan talun merasa kurang puas dengan $\mathrm{AD} / \mathrm{ART}$ yang ada pada gapoktanya.

\section{Kesimpulan}

Skor penilain kepuasan petani terhadap aspek organisasi gapoktan sebesar 549 point, yang bermakna bahwa petani cukup menerima dengan aspek organisasi dari gapoktan masing-masing, dari 7 aspek hanya ada 1 aspek yang berbeda nyata yaitu 


\section{Jurnal Sains Peternakan}

Volume 8 No. 1, Juni 2020, pp:12-21

ISSN 2579-4450

aspek kepuasan bagi petani dari segi aspek organisasi AD/ART Gapoktan. Sedangkan hasil analisis IPA dengan diagram kartesius menunjukan bahwa point 1 yaitu tentang kepuasan petani akan AD/ART Gapoktan di kecamatan Talun belum bisa memberikan kepuasan pada petani. Banyak faktor yang mempengaruhi pemberian nilai dari kuisioner yang diberikan pada responden, faktor utama adalah pemahaman responden untuk memahami soal, faktor pemahaman ini sangat dipengaruhi oleh tingkat pendidikan danumur.

\section{DAFTAR PUSTAKA}

Farida, I. 2012. Persepsi Petani Terhadap Kompetensi Penyuluh Pertanian Lapangan Di Kecamatan Pontang, Kabupaten Serang, Provinsi Banten. Sekolah Pasca Sarjana IPB Bogor (diakses repository.ipb.acid, 22 Juli 2016)

Fitriani.D, Rosnita, A. Rifai,.2015. Persepsi Petani Anggota Gapoktan terhadap Kinerja gapoktan Dalam Mengelola Dana Puap Di Kabupaten Kampar Tahun 2015. Sekolah Pasca Sarjana Universitas Riau Pekanbaru.

Peraturan Menteri Pertanian No. 03 /Permentan/SM.200/1/2008. Tentang Pedoman Penyelenggaraan Penyuluhan Pertanian.

Peraturan Menteri Pertanian RI No.67 /Permentan/SM0.50/12/16/tentang pembinaan kelembagaan petani

Putra. R. 2016. Pembentukan dan Pengembangan Gapoktan. Balai Pengkajian dan Teknologi Pertanian Kepulauan Riau. KementrianPertanian

Saraswati, 2012. Penyajian Komunikasi Pertanian Yang Efektif dalam Kegiatan Penyuluhan. https://trustkeeper.wordpress.com diakses 5 Agustus 2016

Undang-Undang RI No. 16 Tahun 2006. Tentang sistem penyuluhan pertanian, perikanan dan kehutanan.

Undang-Undang RI No. 19 Tahun 2013. Tentang perlindungan dan pemberdayaan petani.

Undang-Undang RI No. 19 Tahun 2013 Tentang Kelembagaan Penyuluhan Pertanian Perikanan Dan Yang Bergabung Dalam Gapoktan Dan Petani Lainnya. 